\title{
Total orthotopic allogeneic small bowel transplantation in rats: effect of allograft irradiation combined with cyclosporine-A therapy
}

\author{
R E Saat, R W F de Bruin, E Heineman, J Jeekel, R L Marquet
}

\begin{abstract}
Rejection and graft versus host disease are prominent features in small bowel allotransplantation in rats. Cyclosporine treatment of the recipient and irradiation of the donor were used to circumvent these phenomena in the WAG to brown Norway rat model. Irradiation of the donor with five or $10 \mathrm{~Gy}$ did prevent graft versus host disease but resulted in a more vigorous rejection of small bowel allografts in untreated recipients (mean (SEM) survival times of $11.5(0.4)(n=8)$ and $7.5(0.9)(n=11)$ days respectively, versus $16.6(2.6)$ days $(\mathbf{n}=17), \mathbf{p}<\mathbf{0 . 0 1})$. Cyclosporine treatment of the recipient $(25 \mathrm{mg} / \mathrm{kg}$ on days $0,1,2,4$, and 6 after transplantation) led to a mean (SEM) survival time of $38.3(8 \cdot 5)$ days $(n=10) ; 20 \%$ of the animals developed graft versus host disease. Combined with 5 Gy donor pretreatment, a similar survival was obtained without occurrence of graft versus host disease. However, cyclosporine treatment combined with $10 \mathrm{~Gy}$ led to a significant shortening of graft survival (23.1 (6.8) days, $n=9)$. These results suggest that although irradiation is very effective in preventing graft versus host disease, high dosages may accelerate rejection either by making the graft more vulnerable to rejection or by completely removing the immunosuppressive effect of graft versus host disease.
\end{abstract}

Various experimental studies on the rejection of small bowel allografts have shown that under certain immunological conditions, immunocompetent cells in these grafts can cause graft versus host disease (GVHD). ${ }^{1-4}$ While the occurrence of this reaction in well defined inbred systems has been conclusively documented, its importance in outbred systems is uncertain. In a previous study we successfully ameliorated GVHD in the WAG to BN rat model using whole body irradiation of the donor with $10 \mathrm{~Gy} .{ }^{5}$ The effectiveness of donor irradiation had been shown previously in a parent to $F 1$ hybrid rat model in which the donors were irradiated with $7,9 \cdot 5$, and $10 \mathrm{~Gy}$ before small bowel transplantation. ${ }^{267}$ In this study we investigated the effects of combined cyclosporine treatment and donor irradiation because we had evidence that irradiation of the donor leads to accelerated rejection of the graft. ${ }^{5}$ We wondered whether cyclosporine could reverse this effect. Earlier we found that cyclosporine, used alone, was not effective in consistently producing long term survivors in the WAG to $\mathrm{BN}$ donor-host combination. ${ }^{8}$ In this study we show that the effect of cyclosporine on GVHD is less pronounced than its effect on rejection, as shown earlier by Kirkman. ${ }^{9}$ In large animal models cyclosporine proved to be less successful than in certain rat strain combinations. ${ }^{10-17}$ Two recent studies in pigs, using ex vivo irradiation of the transplant with $0.5 \mathrm{~Gy}$, a very low dose, combined with cyclosporine therapy of the recipient showed no effect on host survival time compared with cyclosporine monotherapy. ${ }^{1819}$ Because the immunological problems of large animal models resemble the problems in our WAG to $\mathrm{BN}$ rat model, this model is highly suitable for investigating the effect of irradiation combined with cyclosporine treatment.

\section{Methods}

ANIMALS

A fully allogeneic donor-host model was employed by using inbred WAG ( $\mathrm{RT}^{\mathrm{u}}$ ) rats as donors and inbred $B N\left(R T 1^{n}\right)$ rats as recipients. The rats weighed between $200-350 \mathrm{~g}$.

\section{OPERATIVE PROCEDURES}

Donors were fasted for 24 to 48 hours with water ad libitum. All procedures were performed under ether anaesthesia. The method of orthotopic small bowel transplantation has been published recently. ${ }^{5}$ Briefly, the small bowel was double tied and cut $1 \mathrm{~cm}$ distally to the ligament of Treitz and 1-2 cm proximally to the cæcum. The graft was harvested along with the attached vascular pedicles, consisting of the portal vein and the superior mesenteric artery, including an aortic cuff. The graft was flushed via the superior mesenteric artery with 1-2 ml cold Hank's balanced salt solution (HBSS), and stored in cold HBSS while the recipient was prepared. In the recipient, the infrarenal aorta and inferior caval vein were isolated and end to side anastomoses were performed betwen the graft superior mesenteric artery and the aorta, and the graft portal vein and inferior caval vein, respectively. The host's small bowel was resected and the donor small bowel was anastomosed end to end, proximally with the duodenum, distally with the remnant of the ileum at $1-2 \mathrm{~cm}$ from the cæcum. At the end of the operation all rats received a single dose of 20000 IU procaine penicillin G and $20 \mathrm{mg}$ dihydrostreptomycin subcutaneously (Depomycine, Gist-Brocades, The Netherlands).

After operation, the rats were permitted their 
normal diet (Hope Farm diet for rat and mouse No 1410) and water ad libitum. They received no antibiotics in the postoperative period. To get an overall clinical impression of graft function and occurrence of GVHD, the rats were weighed five times a week. Increase in weight was considered to be the most important indicator of acceptable small bowel function. All deaths within four days were considered to be technical failures. After death, necropsy was performed to confirm or exclude rejection.

\section{IMMUNOSUPPRESSION}

Cyclosporine (Sandoz, Basel, Switzerland) was dissolved in olive oil to a concentration of $25 \mathrm{mg} /$ $\mathrm{ml}$ and was administered intramuscularly in doses of $25 \mathrm{mg} / \mathrm{kg}$ on days $0,1,2,4$, and 6 after transplantation. The first dose was given immediately after operation.

\section{IRRADIATION}

Whole body irradiation with doses of 5 or $10 \mathrm{~Gy}$ was performed with a Gammacell 40 cæsium 137 irradiation unit (Atomic Energy of Canada, Ltd), one to four hours before transplantation.

\section{GVHD}

The severity of GVHD was estimated by clinical grading as follows:

Grade 1, light redness of ears, snout, and paws;

Grade 2, moderate redness of ears, snout, and paws; light hair loss and diarrhoea;

Grade 3, severe redness of ears, snout, and paws; alopecia, generalised dermatitis; and profuse diarrhoea.

\section{EXPERIMENTAL GROUPS}

Six groups were distinguished (see Table) as follows:

Group 1, controls, WAG to BN, no immunosuppressive therapy, $\mathrm{n}=17$;

Group 2, irradiation of the donor with $5 \mathrm{~Gy}$, $\mathrm{n}=8$;

Group 3, irradiation of the donor with $10 \mathrm{~Gy}$, $n=11$. The results for this group have been published before. ${ }^{5}$

Group 4, administration of $25 \mathrm{mg} / \mathrm{kg}$ of cyclosporine on days $0,1,2,4$, and 6 after transplantation, $\mathrm{n}=10$.

Group 5, irradiation of the donor with $5 \mathrm{~Gy}$ in combination with $25 \mathrm{mg} / \mathrm{kg}$ of cyclosporine given on days $0,1,2,4$, and 6 after transplantation to the recipient, $\mathrm{n}=9$.

TABLE I Schedule of graft pretreatment and immunosuppression

\begin{tabular}{lrll}
\hline Group & No & Pretreatment $^{\star}$ & Immunosuppression $\dagger$ \\
\hline 1 & 17 & - & - \\
2 & 8 & $5 \mathrm{~Gy}$, in vivo & - \\
3 & 11 & $10 \mathrm{~Gy}$, in vivo & - \\
4 & 10 & - & CsA \\
5 & 9 & $5 \mathrm{~Gy}$, in vivo & CsA \\
6 & 9 & $10 \mathrm{~Gy}$, in vivo & CsA \\
\hline
\end{tabular}

* Whole body irradiation was performed $1-4$ hours before transplantation using a cæsium 137 gamma source.

+ Cyclosporine A (CsA) was given intramuscularly in doses of 25 mo/kg on days $0,1,2,4$
TABLE II The effect of donor pretreatment and immunosuppression on the survival of orthotopic small bowel transplantation in rats

\begin{tabular}{lll}
\hline Group & Survival(days) & Mean $(S E M)$ \\
\hline 1 & $6,6,6,7,8,8,13^{\star}, 14,14,15,15,19^{\star}$, & $16 \cdot 6(2 \cdot 6)$ \\
2 & $21^{\star}, 24,27^{\star}, 31^{\star}, 47^{\star}$ & $11 \cdot 5(0 \cdot 4)$ \\
3 & $10,11,11,11,11,12,12,14$ & $7 \cdot 5(0 \cdot 9)$ \\
4 & $5,5,6,6,6,6,6,7,10,12,13$ & $38 \cdot 3(8 \cdot 5)$ \\
5 & $8,11,13,13,21,55,59+, 65,66^{\star}, 72$ & $42 \cdot 7(6 \cdot 8)$ \\
6 & $11,17,31,34,49,55,57,58,72$ & $23 \cdot 1(6 \cdot 8)$ \\
\hline
\end{tabular}

^ Grade 1-2 severity of graft versus host disease; † grade 3 severity of graft versus host disease.

Groups 2 and 3 significantly worse compared with group 1, $\mathrm{p}<0.01$; group 2 significantly better compared with group 3 , $\mathrm{p}<0.02$; group 5 not significantly different from group 4; group 6 significantly worse compared with group $4, p<0.01$.

Group 6, irradiation of the donor with $10 \mathrm{~Gy}$ in combination with $25 \mathrm{mg} / \mathrm{kg}$ of cyclosporine given on days $0,1,2,4$, and 6 to the recipient, $\mathrm{n}=9$.

STATISTICS

The survival data were statistically analysed using the Wilcoxon test for group comparison.

\section{Results}

Table II shows that untreated control rats died after a mean (SEM) survival time of 16.6 (2.6) days. Six of 17 rats showed grade 1-2 symptoms of GVHD for three to four days. In groups 2 and 3 , whole body irradiation of the donor with 5 and $10 \mathrm{~Gy}$ respectively resulted in a complete absence of GVHD. Surprisingly, the survival times in both groups were significantly shorter than those in the control group $(11.5(0.4)$ and $7.5(0.9)$ days respectively $v 16.6(2.6)$ days, $\mathrm{p}<0.01)$. The accelerated graft rejection was more vigorous in group 3 than in group $2(\mathrm{p}<0.02)$. Rats in group 4 that received $25 \mathrm{mg} / \mathrm{kg}$ cyclosporine, survived for a mean (SEM) of $38 \cdot 3(8 \cdot 5)$ days; two of 10 rats developed clinical symptoms of GVHD. Pretreatment with $5 \mathrm{~Gy}$ in combination with cyclosporine (group 5), produced no significant difference in survival time when compared with group $4(47 \cdot 2$ (6.8) v $38.3(8 \cdot 5)$ days). However, none of the rats in group 5 showed signs of GVHD or peritonitis. One rat died on day 58 as a result of a late technical complication: stenosis of the proximal intestinal anastomosis. In group 6 , irradiation with $10 \mathrm{~Gy}$ and cyclosporine therapy resulted in a mean survival time that was significantly shorter than that found in group $4(23 \cdot 1$ $(6.8) v 38.3(8.5)$ days, $\mathrm{p}<0.01)$. At necropsy, four of the recipients that died in the first week showed symptoms of peritonitis as a result of a vulnerable, glassy transplant. No GVHD was observed in this group. Most rats in groups 4, 5 , and 6 that survived more than three to five weeks increased in weight. In comparison with the weight gain observed earlier in a syngeneic (WAG-WAG) study, in which the donor was irradiated with $10 \mathrm{~Gy}$, however, the weight gain was minimal.

\section{Discussion}

This study clearly shows that irradiation of the donor very effectively prevents the occurrence of 
clinical GVHD. In addition, when GVHD is ameliorated or absent in a fully allogeneic rat model, the acute rejection in untreated recipients is accelerated. This vigorous rejection can be explained by the assumption that irradiation with $10 \mathrm{~Gy}$ releases more immunocompetent cells in the peripheral circulation of the recipient than irradiation with $5 \mathrm{~Gy}$. Although we cannot exclude this effect, it is our opinion that the vigorous rejection can only be controlled by cyclosporine therapy when GVHD is not completely abrogated. The mechanisms that are probably responsible for these results have been described in experiments on GVHD in bone marrow transplantation. ${ }^{2021}$ These studies showed that a GVH reaction can induce a state of permanent suppression of cell mediated and of humoral immune responses.

This functional abnormality of $\mathrm{T}$ cells or $\mathrm{B}$ cells, or both, is probably related to a maturation defect. ${ }^{20}$ Therefore the absence of GVHD, with its inherent immunosuppressive effect, is the most plausible explanation for the vigorous rejection that occurred in irradiated donors. From studies in a semiallogeneic parent to an F1-hybrid rat model it is known that irradiation with $5 \mathrm{~Gy}$, in contrast to $10 \mathrm{~Gy}$, failed to prevent the onset of GVHD. ${ }^{8}$ Extrapolating these data to our results, we presume that the immunosuppressive effect of subclinical GVHD was responsible for the beneficial effect on the survival time when donors were irradiated with $5 \mathrm{~Gy}$ compared with $10 \mathrm{~Gy}$. Moreover, the absence of clinical GVHD may be of clinical importance.

Until now it has been uncertain to what degree, if any, GVHD will complicate human small bowel transplantation. Under the assumption that GVHD will develop after small bowel transplantation, strategies have to be developed to circumvent this complication. In theory, drug treatment or irradiation of the transplant before surgery would be the ideal method to inactivate donor lymphocytes. Practically, irradiation is the easiest procedure and can be performed ex vivo without losing its effect. ${ }^{?}$

Obviously, the major problem in small bowel transplantation remains the vigorous rejection process and its suppression. Cyclosporine will be the most important drug in any standard immunosuppressive regimen. This study gives indirect evidence that irradiation of the donor in combination with cyclosporine is useful only when some immunocompetent cells in the graft, capable of producing a subclinical GVHD whose immunosuppressive effect is beneficial to the survival of the allografts are left. It is necessary to quantify further the donor irradiation dose that will result in the optimal interaction between the occurrence of GVHD and rejection of the graft.

1 Deltz E, Ulrichs K, Schach T, et al. Graft versus host reaction in various target organs after small intestine transplantation. Transplant Proc 1981; 13: 1215-6.

2 Monchik GJ, Russell PS. Transplantation of small bowel in the rat: technical and immunological considerations. Surgery 1971; 70: 693-702.

3 Schraut WH. Current status of small-bowel transplantation. Gastroenterology 1988; 94: 525-38.

4 Schraut WH, Lee KKW, Dawson PJ, Hurst RD. Graftversus-host disease induced by small bowel allografts. Transplantation 1986; 41: 286-90.

5 Saat RE, Heineman E, de Bruin RWF, Marquet RL, Jeekel J. Total orthotopic allogeneic small bowel transplantation in rats: Attempts to ameliorate the graft-versus-host disease by irradiation and transfusions to the donor. Transplantation 1989; 47: 451-3.

6 Deltz E, Ulrichs K, Schach T, et al. Graft versus host reaction in small bowel transplantation and possibilities for its circumvention. Am $\mathcal{F}$ Surg 1986; 151: 379-86.

7 Lee KKW, Schraut WH. In vitro allograft irradiation prevents graft-versus-host disease in small bowel transplantation. 于 Surg Res 1985; 38: 364-72.

8 Saat RE, de Bruin RWF, Heineman E, Jeekel J, Marquet RL. Limited efficacy of cyclosporine-A in preventing rejection and graft-versus-host disease in orthotopic small bowel and graft-versus-host disease in orthotopic small bo
transplantation in rats. Transplantation 1990; 50: 374-7.

9 Kirkman RL. Small bowel transplantation. Transplantation 1984; 37: 429-33.

10 Schraut WH, Lee KKW, Sintrin M. Recipient growth and nutritional status following transplantation of segmental small bowel allografts. F Surg Res 1987; 43: 1-9.

11 Hatcher PA, Deaton DH, Bollinger RR. Transplantation of the entire small bowel in inbred rat using cyclosporine. Transplantation 1987; 43: 478-84.

12 Harmel RP, Stanley M. Improved survival after allogeneic small intestinal transplantation in the rat using cyclosporine

13 Lee KKW, Schraut WH. Structure and function of orthotopic small bowel allografts in rats treated with cyclosporine. Am 7 Surg 1986; 151: 55-60.

14 Schimazu R, Grogan JB, Raju S. Long-term survival of orthotopic allografts in the rat treated with short-term lowdose of cyclosporine. Transplantation 1988; 46: 673-7.

15 Kirkman RL. Small bowel transplantation. In: Morris PJ ed. Progress in transplantation. Edinburgh, Churchill, Living stone. 1987: 75-97.

16 Craddock GN, Nordgren SR, Reznick RK, et al. Small bowel transplantation in the dog using cyclosporine. Transplantation 1983; 35: 284-8.

17 Diliz-Peres HS, McClure J, Bedetti C, Starzi E. Successful small bowel allotransplantation in dogs with cyclosporine and prednison. Transplantation 1984; 94: 12-16.

18 Grant D, Duff J, Zhong R, et al. Successful intestinal transplantation in pigs treated with cyclosporine. Transplantation 1988; 45: 279-84.

19 Pritchard TJ, Kirkman RL. Small bowel transplantation. World f Surg 1985; 9: 860-7.

20 Seddik M, Seemayer TA, Lapp WS. The graft-vs-host reaction and immune function. Transplantation 1984; 37: 281-6.

21 Stet RJM. Graft-vs-host reaction in the rat [Thesis]. Groningen, The Netherlands: University of Groningen, 1987. 